\title{
Text, Sound and Videotape: The Future of Qualitative Data in the Global Network
}

\begin{abstract}
We are currently seeing a new culture emerging in the social sciences, of a new form of secondary analysis - that of primary qualitative data. It has come about largely as a result of the moves by British social science funding organisations towards formalising archiving policies of data created in the course of research they fund. Funders want added value from research and believe in sustaining a solid research base for the future, in the form of the preservation of empirical findings. Now, this includes qualitative data in addition to quantitative.

However, not only is this is a new methodological approach for traditional qualitative researchers it is also challenging the way qualitative researchers view ownership of 'their' raw data. New ideas about sharing and providing access to qualitative data are emerging and in the UK, this is being championed by the Qualidata Resource Centre at the University of Essex.

This paper seeks to address a number of issues. From an archival point of view, how do qualitative data differ from quantitative data? Second, what might the implications be for the acquisition, preservation, dissemination and re-use of qualitative data archives for Data Archives? Thirdly, I want to discuss the kinds of procedures required to document and provide access to qualitative data. Inherent in this are the special problems relating to confidentiality of some qualitative materials, and I will suggest ways of overcoming these. Finally, I want to raise a number of questions relating to how the traditional Data Archives might want to consider acquiring, storing and disseminating qualitative data. Is it in their interest to acquire them? What kind of infrastructure needs to be in place to accomplish this?
\end{abstract}

Background to archiving qualitative data in the UK The ESRC Qualitative Data Archival Resource Centre (Qualidata) is supported by the Economic and Social Research Council (ESRC) and is located in the Department of Sociology at the University of Essex. The Centre was established in 1994 in order to redress the balance in the bias towards archiving quantitative data from British social science research. It currently has funding up until the end of September 2000. Our relationship to the UK Data Archive is one of a younger sibling.

The Data Archive was set up in 1967 by the Economic and Social Research Council (ESRC) in order to retain the most significant machine-readable data from the research, which it funds. In order to achieve this, ESRC instigated a 'Datasets Policy' whereby all machinereadable data generated from ESRC awards should be offered for archiving. There was, however, a significant loophole in this policy. Although the advances of word processing now mean that most research of any kind is machine-readable, until recently most machine-readable data was statistical, based on surveys. Qualitative research was paper-based. Thus the Data Archive received only a proportion of the raw research data funded by the ESRC.

As Paul Thompson, Director of Qualidata, stated in his 1991 pilot report to the ESRC, 'there was no intellectual reason for this'. Qualitative and quantitative research are equally based on comparison. Classic re-studies include not only Rowntree's three surveys of poverty in York, and Llewellyn Smiths' repeat of Booth's poverty survey in London, but also the two successive multi-method community studies of Banbury, or, to take an anthropological instance, the controversial restudy and reinterpretation by Oscar Lewis of Redfield's Tepotzlan in Mexico $^{1}$.

It is not therefore clear why the early Social Science Research Council (SSRC) did not feel the need to provide for the archiving of non-machine readable research data. Perhaps it was simply felt that there were enough existing archives to ensure that significant material was saved. But in practice, that was certainly not the case. Some qualitative material was archived, but usually in special temporary deposits. Thus the interviews on which Professor George Brown's notable studies of the social origins of depression, are based, were for many years held at his Medical Research Council Unit, of which the longterm future remained until very recently uncertain. Similarly, the material from Paul Thompson's national study of 'Family Life and Work Experience before 1918', a unique and unrepeatable set of 444 interviews with men 
and women born before 1918, were kept on a short-term basis in a special room at the Sociology Department at Essex, and consequently became the basis of a series of books and articles by visiting scholars, but had no secure future. More generally, little attempt of any kind was made to archive research material.

When a small pilot study commissioned by the ESRC was carried out in 1991, it was revealed that $90 \%$ of qualitative research data was either already lost, or at risk, in researchers' homes or offices. Even with the $10 \%$ 'archived', it turned out that many of the so-called archives had none of the basic requirements of an archive, such as physical security, public access, reasonable catalogues, or with recorded material, listening facilities. It was estimated that to create a resource on the scale of that at risk would cost at least $£ 20$ million. For the older material, moreover, the risk was acute, and the need for action especially urgent.

\section{Qualidata's mission}

Qualidata was set up by the ESRC with a dual mission. The first was a rescue operation aiming to seek out the most significant material created by research from past years. The second was to work with the ESRC and the Data Archive to ensure that for current and future projects the unnecessary waste of the past does not continue. Qualidata is not an archive itself: it is both a clearinghouse and an action unit. Its role is to locate and evaluate research data, catalogue it, organise its transfer to suitable archives, and publicise its existence to researchers and encourage re-use of the collections. We maintain a catalogue, Qualicat, located on the World Wide Web, which provides information both about qualitative datasets archived by the Centre and those identified by the Centre as having already been archived. The catalogue structure follows that of CESSDA very closely, with some new and modified fields to suit the characteristics of qualitative data.

The Centre consults with the ESRC and other funding bodies on, the now explicit, qualitative aspects of the Datasets Policy and provides advice to researchers on the implications of archiving for research, both through organised workshops and through individual consultations. The Centre also aims to provide a general stimulus to the practice and standards of qualitative research, especially in documenting social science research in Britain, as well as encouraging a more active interface between qualitative and quantitative research.

\section{How do we define qualitative data?}

Qualidata is concerned with research data arising from the range of social science disciplines, including sociology, social policy, anthropology, social and economic history, political science, social and human geography and social psychology. We define qualitative data as data collected using a qualitative methodology, which contrasts markedly to the traditional quantitative approach. Qualitative research is defined by openness and inclusiveness, aiming to capture participants' lived experiences of the world and the meanings they attach to these experiences from their own perspectives. Moreover, a qualitative perspective encompasses a diversity of methods and tools rather than a single one. Our definition of qualitative includes in-depth or unstructured interviews, field and observation notes, unstructured diaries, personal documents, photographs and so on, in typed, hand-written, images, audio and video format and either as a digital or non-digital representation.

\section{Where do we put the data?}

One of Qualidata's ongoing objectives is the selection of public repositories suitable and willing to receive research material. Given that a high proportion of archives used by earlier researchers had proved to be inadequate, a proper evaluation of each potentially suitable archive is essential. A programme of visits to key national archives took place during the first six months of the project, and one of our on-going activities is to liase with new repositories which have special collecting priorities. Meeting with traditional archivists raises a number of interesting points about how these professionals view the acquisition and cataloguing of qualitative data collections, and about their relationships with traditional librarians. Although we did have a professional archivist on the team at the beginning, essential for gaining credibility with traditional archivists, we are now, primarily a team of social scientists who have adopted a cross-fertilised approach of data archiving and traditional archiving.

Repositories willing to accept qualitative deposits from Qualidata include:

- The Data Archive, University of Essex

- Renowned University archival repositories across Britain

- British Library of Political and Economic

Science, London School of Economics

- The Modern Records Centre, University of Warwick

- National Social Policy and Social Change

Archive, University of Essex

- British Library (Sound Archive and

Manuscripts)

- Specialist Institute Libraries

- Institute of Criminology, University of

Cambridge

- Contemporary Medical Archives Centre,

Wellcome Institute, London

- British Universities Film and Video Council,

London

- National Museum Archives

- Imperial War Museum, London

- Labour History Archive, Manchester

- Science Museum, London 
Each repository specialises in a number of fields of research. Some had not acquired qualitative research data before, but were very keen to begin. Furthermore, some have now acquired valuable collections of qualitative social science data and wish to keep acquiring data from us in their particular areas of interest.

\section{Evaluating qualitative data for archiving}

Qualidata is a small unit: two fulltime and two part-time senior staff; and four part-time processing officers. Masses of data are out there, and the suitability of data for archiving is assessed according to a set of criteria developed by Qualidata. Potential depositors are first invited to submit a sample of data, such as a transcript, to Qualidata, together with some documentation about the project. This includes the following requirements for datasets:

- Of a sufficiently qualitative nature

- In good physical condition, e.g. good quality recordings, abbreviations explained etc.

- Can be made freely accessible for academic use

- Perceived as having potential for secondary analysis

- Be able to fit in with existing collections

- Sufficient documentation to enable informed reuse

- Copyright, confidentiality and informed consent situation is satisfactory

- Resources needed to make material available do not outweigh potential for re-use (If the requirements of archiving are taken into consideration from the outset of a project, it is possible to keep extra work to a minimum. For example, ESRC applicants are now encouraged to include in their schedule and budget the necessary resources by which to prepare data for archiving) - A suitable repository can be found (although if the materials are considered very high priority then Qualidata will house them temporarily).

\section{Processing the data}

The Centre undertakes processing work necessary both to ensure that data archived conform to legal and ethical guidelines, for example to abide by commitments of confidentiality given to research participants, and to achieve the greatest practicable accessibility and usability for the data.

Any acquiring organisation will know that some collections of data arrive in a very disorganised state whereas others will be immaculately filed, indexed and labelled. The amount of time and resources required to document material from a previous qualitative study very much depends on how old the material is and much there is. Qualidata does accept hand-written material, such as field notes, but where totally illegible, may need to be retyped.
This is an expensive process and is only done in the most exceptional circumstances e.g. where the material is felt to be particularly valuable. We also encounter problems with audio-recordings without summaries or transcripts, as transcripts are almost always requested by researchers. In extreme cases, summaries may be carried out by Qualidata. Digitisation is also sometimes undertaken to give greater accessibility of datasets.

\section{Preservation of confidentiality and informed consent in qualitative data}

Since the archiving of qualitative data is fairly recent in terms of the history of social science, I would like to outline some of the procedures we have set up for safeguarding the anonymity of informants. The research community has long recognised the importance of respecting the rights of research participants. These rights take two principal forms: the right to have their identity protected (if so desired); and the right to make an informed decision about the uses made of the data that they provide. Personal information should be kept confidential, whether or not a pledge of confidentiality has been given to research participants, and should be stored in a secure manner according to the provisions of the UK Data Protection Act (1998).

Various professional and commercial organisations within the field of social science research have their own ethical guidelines and rules of conduct. Whilst some offer more detail with regards to issues like interviewing in difficult circumstances and preservation of anonymity, all present issues regarding the kind of ethical judgements researchers must make when embarking on a research project. The principal for preserving privacy, as articulated for example, in the British Sociological Association (BSA) statement, is that of the anonymisation of data. However, only one set of guidelines discusses issues relating to the sharing of research data.

Qualidata has undertaken considerable consultation within the research community, as well as liasing with potential depositors of data, concerning the issues of confidentiality and informed consent. These have undoubtedly been the most frequent causes of concern in the archiving of data. Qualidata has a deep concern both for the rights of participants and the professional integrity and peace-ofmind of researchers, and therefore both the issues of confidentiality and informed consent must be addressed in the context of archiving qualitative material. However, in many ways, adhering to guarantees of anonymity is always problematic. The very nature of qualitative data lends itself to descriptions of the interviewees, their lives and their surroundings, and in doing so, presents a dilemma to the researcher in how much to reveal. Is it really possible to completely disguise a workplace or a village or the central characters in the drama? I believe that future re-users of a qualitative dataset are presented with similar, if not the 
same, issues as the first authors, concerning respecting the rights of participants.

We have produced information sheets relating to the issues of Confidentiality and Informed Consent and

Confidentiality, Consent and Copyright in the Interviewing of Children, both available from the Centre upon request or via its WWW site. These information sheets describe the current legal and ethical situation and suggest solutions by which to respect the rights of participants. Of course, Qualidata recognises that some datasets cannot be ethically archived, particularly those that address sensitive issues.

The options used by Qualidata for preserving confidentiality, where appropriate are:

- Anonymisation of material is just one option available for helping make qualitative data accessible as a future research resource. It can include the removal of identifiers; the use of pseudonyms; and the use of other techniques for disguising the link between individual identifiers and data. It is, of course, important to arrive at an appropriate level of anonymisation to ensure that the data is not distorted to a degree, which devalues their potential for reuse.

- A period of closure. Where appropriate, a specified period of closure can be applied, although some archives are naturally resistant to accepting material that cannot be used for a long period of time. The saving grace for extremely sensitive materials is that time is of the essence. In 50 years time any tensions should have dissipated, and the information will become history.

- Restricted access (operated by the archive). Access to the data can be restricted to bona fide researchers for genuine research purposes.

- Restricted access (operated by the depositor). It is possible to make it a condition of deposit whereby all potential secondary researchers must liase with the depositor to discuss their intentions for secondary analysis. The depositor may choose to only give access when satisfied that the data will be used in an appropriate manner in each case. Traditional archivists are well used to this approach.

- User undertaking not to disseminate any identifying information. Most archives operate user undertakings not to breach confidentiality by using identifiable information in published work. This condition is, of course, more effective if used in conjunction with restricting access to bona fide researchers. Such a written undertaking does have contractual force in law. Furthermore, the good reputation of a secondary user depends upon abiding by these undertakings.
- Re-contacting participants. It is possible for investigators to go back to research participants to obtain consent for deposit in a public archive, this being something with which Qualidata can sometimes assist. This is very time consuming but usually productive.

- Gaining informed consent in writing for material to be placed in an archive (at the time of fieldwork, but usually after an interview). Qualidata has a sample Informed Consent form, which is also available upon request. This also allows for transfer of copyright

Depositors have absolute control in setting the terms and conditions for access. An agreement is then set up between the deposit and recipient repository to implement these terms and conditions. Secondary users given access to the data must be made aware of such terms and conditions, and should abide by them. In this respect, as data archivists, we place much emphasis on the responsibility of the secondary user.

Why are qualitative researchers sceptical about sharing and re-using qualitative data?

I would like to digress for a moment or two and consider why qualitative researchers show such scepticism towards archiving. This is simply because there has not been an established culture in social science for re-using someone else's qualitative data. Oral historians do use other sources, but this is because they are primarily social historians.

To establish why sociologists have not used colleagues' data, we must first recognise that qualitative researchers are a different breed from the ranks of the quantitative brigade. Some, but not all, see the concept of secondary analysis as purely about number crunching, and others feel very threatened by the idea of sharing or making data accountable. There are a number of reasons for this doubt and worry.

1. It is far more interesting to do your own fieldwork, even if it is extremely costly and possibly may be replicating previous studies of similar populations (at the expense of the taxpayer!)

2. Generally, qualitative social 'scientists' are just not used to making their findings accountable. They are worried about others seeing their data, and possibly picking holes in them. Some argue that certain approaches used in qualitative research, for example, grounded theory (Glaser and Strauss $1967^{2}$ ) which opposes the scientific paradigm of testing hypotheses, do not lend themselves to verification.

3. Many researchers we have spoken to feel very strongly that, through fieldwork, they have established a special bond with their interviewees. Many also have promised informed consent at the time of interview 
which precludes the use of the participants' contributions for anything other than their own eyes or, at least, the current piece of research.

4. Some researchers are concerned that their material cannot be used sensibly without the accumulated background knowledge which they have acquired during its collection. This is particularly so with longitudinal studies of a group where the researcher feels that a special rapport has been developed without which the material may be meaningless. Thus the essential contextual experience of 'being there' cannot be shared.

We believe there is a solution to each of the negative points raised above:

1. To gain a more informed approach and to stop the proliferation of repetitive work, new studies should make more attempts to delve into earlier related research and try to include some comparative element. In order to be able to accomplish this, a firm bedding of archives across the UK needs to be cultivated on a regular basis and nurtured thereafter.

2. If we are to accept the label 'scientist', then we should adopt the scientific model of accountability, reliability and validity. The quality of social research is highly variable, and in the UK there are no quality control standards for qualitative studies (except for market research ${ }^{3}$ ). We believe it is bad practice for raw data not to be available for future scholars and, furthermore, detrimental to the progress of history. As far as I am aware, it is unheard of for a social science journal to cite access to the original source of data, as is necessary in most natural scientific journals.

3. Interestingly enough, the complete protection of anonymity that researchers sometimes offer their participants is untenable - a first publication which a journalist then seizes upon may undermine this promise with a misguided stroke of a pen. In essence it is impossible to promise total anonymity. In contrast, we have found that when recontacting participants to gain permission for archiving, the majority seem to be in favour, even though this wasn't mentioned at the time of fieldwork. Our experiences tell us that, providing their contribution is not abused, for example, their identifying characteristics are not cited (if they choose them not be), they are happy for serious scholars of the future to look at the raw materials. Most people do believe that research is for the public good, and that their contribution will be used in some way to create a better informed society, and even go some way towards implementing policy changes.

Contractual archival policies mean that investigators must now either rethink negotiations about informed consent and be prepared to discuss with their participants, at some stage, access to data beyond their own team.

4. The 'being there counts' argument is understandable but also an easy opt out of being prepared to share data. Indeed, there are instances where research data are, in a sense 're-used', by the investigator themselves. For example, some principal investigators who write the final articles resulting from a project have employed research staff or a field force to collect the data. Similarly, for those working in research teams, sharing one's own experiences of the research is essential. Both rely on the fieldworkers and co-workers documenting detailed notes about the project and communicating them to each other. Of course, audio and videotape recordings enhance the capacity to re-use data without having actually been there. For archives, documentation of the research process provides some degree of the context, and whilst it cannot compete with being there, field notes, letters and memos documenting the research can serve to help aid the original fieldwork experience.

\section{What about the format of data?}

We deal with all formats. Much qualitative data nowadays is digital in the sense that the text is word-processed or hand-written material is scanned, or audio-visual material is in digitally recorded form. Qualidata has developed standards for the documentation of qualitative digital data in liaison with the UK Data Archive. Generally materials are reduced to their simplest form, ASCII, TIFF4, but the Data Archive also accept Rich Text Format (RTF) and Adobe's Portable Document Format (PDF).

We put digital data alongside paper-based materials in repositories or, where possible, offer it to the Data Archive at Essex. Data from mixed methods studies are usually offered first to the Data Archive, for example, so those indepth interview transcripts sit alongside the statistical dataset. The Data Archive are experienced in handling, storing and disseminating textual data, and presently have the advantage over some traditional repositories in being able to keep up with changing media and storage technologies. However, for acquisition by the Data Archive, textual data must be, as far as possible, anonymous. Preservation of confidentiality is addressed below.

Far more qualitative researchers are now using digital data. The last three years have seen a huge growth in the use of computer-assisted qualitative data analysis software (CAQDAS) packages in qualitative research. CAQDAS software, such as NUDIST and ATLAS-ti, is rapidly becoming the accepted tool for handling the description and interpretation of qualitative data. For Qualidata issues about preservation of data from these packages is something we 
have had to address with some urgency. These are proprietary software packages and in the past it has not been possible to import and export data from one package to another. Qualidata has developed guidelines on what to keep for archival purposes - i.e. reducing the data to its simplest form - ASCII text or RTF. As expected, in the past year we have seen software developers taking steps to encourage sharing between packages, for example adding export and import facilities to their programmes, and even beginning to build XML export features.

\section{Digitisation- where are we going and what are we keeping?}

The Data Archive in the UK archives primarily numerical, textual data: documentation for datasets is now stored in image format mostly in the form of PDF files; and more recently they have also begun to acquire image based datasets.

Qualidata is currently working on a large-scale digitisation project. This is the preservation of Professor George Brown's life's collection of research data. The major focus of the work is on the role of psychosocial factors in the onset, course and chronicity of, and recovery from, clinical depression (a major public health problem). ${ }^{4}$ The distinctive feature of George Brown's approach has always been the ability to combine both qualitative and quantitative aspects of the same data. The publications resulting from Brown's team reflect this duality in combining a host of statistical tables with a wealth of case history material. Thus the surveys above are all coded and the statistical data for each project will be archived with the Data Archive here at Essex.

Qualidata is image scanning the paper schedules, many of which contain a great deal of annotation in hand written form. The original TIFF4 files and a final PDF file for each case (patient) will still archived. PDF has been chosen by the Data Archive as a suitable archival format, as have many other institutions in Britain. However, we can never be sure whether this format may become extinct, and at the very least we would hope if it did, that conversion to the new formats would be an option. Perhaps we can allow ourselves to relax just a little, as we move into a climate of technological sharing and interoperability.

But when do we throw away the paper? A number of options come to mind, in no particular order:

- When our physical storage space is full up - When we are confident we have a permanent representation

- When the paper starts degrading

In my own experience, thinking back to the forty four filing cabinets worth of George Brown's data, I am terrified of getting rid of any of them! They are going to be available in electronic book form, and as safe as they could be in a prestigious Data Archive, but what if....? To avoid this panic and to appease our sense of sentimentality, our current strategy is to keep samples of original data, so for each project we will select about ten cases and these will be placed with a suitable academic (paper based) repository. If scholars still want to set eyes upon the original documents, they can!

\section{Can traditional archives cope with digital non- numerical data?}

Well, in short, some can and some can't! Some of our host repositories have the facilities to provide copies of, say transcripts on disk, whereas others just can't provide that service. This is usually simply a case of under resourcing. It is not uncommon in the traditional British archive world to see one, or at best two, archivists responsible for sorting, cataloguing, housing, and providing access to archives. This leaves little time for digitisation programmes and resources may not stretch to obtaining high-powered computers for storage. Reviews of electronic documents in personal papers and organised records held by archival repositories in Britain highlight problems of staffing, software, hardware, expertise and dissemination.

The other side of the picture, and of course, an ironic one, is the increasing lack of physical storage space for paperbased archives. Many archives are full up with paper documentation, and those with inadequate storage facilities are using hot or damp basements for storage.

Microfilming and digitising saves on storage space, but does not necessarily represent a cheaper option: filming and scanning are expensive operations and the maintenance of electronic records in the long-term involves periodic transfers of data to new media and software. Technological changes - and the ever-reducing cost of computer storage will undoubtedly mean that digitisation becomes a more attractive option over time, not least because it allows the records themselves to be disseminated electronically.

With the dawning of the Age of the Digital Library, and closer relationships being forged by academic libraries and archives with IT departments, and new centrally funded programmes, I don't imagine archivists will turn away machine-readable versions of transcripts for much longer.

\section{Problem areas for archiving qualitative data}

Video recording and other image (such as photos), and to a lesser extent audio data, all present added difficulties for archiving and it is preferable that participants play a key role in the decision to archive.

\section{Audio-tape recordings}

Tape recordings of interviews are almost always used in qualitative studies. These may be individual interviews, focus groups, observation and naturally occurring conversation. For some projects, full transcription is 
essential, for others summaries may suffice. Methods of transcription also vary: sociologists generally want to capture the words, whereas linguistics are more concerned with recording other contextual features of the interview, such as pauses, laughter, tears etc.

In terms of re-use potential of data, the ideal is to retain the original tape recordings. There is really no substitute for listening to people's own words; a transcription is a subjective interpretation of the real-life conversation. In reality, it is often not possible to archive audiotapes where the material is 'sensitive', without either restricted access, a period of closure and/or retrospective permission from participants.

Anonymising tape recordings in the same way as for the transcripts is vastly time-consuming and prohibitively costly. Blanking out of identifying information on analogue media is also rather pointless as it distorts the data. Perhaps digital audio data may be less problematic. New software is now available for which researchers can edit, anonymise, label and copy their own data with far more ease. Again, this is still labour intensive and in the UK there is still no concensus about what the best audio format is for archival purposes. Current popular options are Minidisc, R-DAT and CD-R, but there is still no consensus on the relative longevity of these media.

\section{The even more problematic case of video-data}

Everything discussed with reference to audio data is worse for video data, with the added complexity of faces. We have not yet been able to archive much interview video data, as researchers have been very anxious about the possibility of identifying participants. There is no way around seeking permission to archive video data, and we are advising that permission is sought either before or after interview, depending on the sensitivity of the research and context of the interview setting. However, it is still evident, at least in the UK, that only a few branches of social science have taken on board the use of video methods: social anthropologists; socio-linguists and discourse analysts and educationalists.

\section{So, should the traditional data archives acquire and store audio, video and multi-media data?}

As technology moves forward many Data Archives across the world will have to begin considering the storage of digitised and indexed data from audio, video and multimedia data. We will see great improvements in storage options and indexing facilities for audio and video data. DVD is an exciting but volatile format and surely will replace audio and video $C D$. Since all Windows operating systems will be supporting it, it looks likely to dominate the market. Whilst it is still very expensive, inevitably costs will drop. the traditional social science data archives to take this route? For example, accepting and storing digitised audio and video of qualitative data creates serious issues regarding confidentiality and access, and also indexing. Whilst most Data Archives do not accept photos, audio or video-tapes, there are other specialist archives in Britain set up to receive and deal with these formats of data (although not with a social science remit). These have established standards and have dedicated working groups e.g. the Digital Archiving Working Group run by the BL, PRO and JISC, and Research Libraries Group. We are seeing guidelines emerging for the preservation on each and every kind of media.

New types of data clearly require specialist staff for evaluation, processing and documentation. The reason that the UK Data Archive is able to acquire textual and image qualitative material is that Qualidata acts as the front-line, engaging in evaluation, processing and documentation of these data. Thus the staff time and expertise to deal with qualitative data are not required of the Data Archive's own personnel, who are busy enough with their own specialist roles. With this infrastructure in place, the Data Archive can provide access to a greater range of social science data.

An alternative model might be for the social science Data Archives' to act in the role of brokers, where storage and access of social science data in say, audio and video formats, can be negotiated through Data Archives established systems, but not necessarily either processed or stored there.

There are now smaller embryonic "qualidatas" growing across Europe. However they are typically run by academics based in sociology departments, and usually have no links with their own country's Data Archive Community. I am helping to build a network of these Centres and hope that the Data Archive Community will begin to take on board the contemporary and historical significance of qualitative data. To do this we all need to communicate and debate the issues I have addressed in this paper.

1. Paul Thompson, 'Report to the ESRC on 'The archiving of qualitative interviews: A Pilot Survey', November 1991.

2. Glaser, B.G. and Strauss, A.L. (1967), 'The Discovery of Grounded Theory: Strategies for Qualitative Research', Chicago: Aldine.

3. BS 7911 is the trademark for the standard adopted by the Market Research Society in 1988 for 'Specification for organizations conducting market research'. This came about partly as a result of the hugely varying quality of qualitative studies in this arena.

But I would like to pose the question: is it in the interest of 
4. The archive will include twelve collections, based on distinct projects dating from 1969 to the present. The earliest and probably best known study to many social scientists and clinicians is the Camberwell Study, conducted from 1969-75 and providing the basis for the eminent book, 'Social Origins of Depression', by Brown and Harris. The team pioneered the Life Events and Difficulties Schedule (LEDS), a survey instrument used to record stressful experiences and significant life events.

* Paper presented at:International Association for Social Science Information Service \& Technology, Building Bridges, Breaking Barriers: the future of data in the global network, Toronto, May, 1999.

Louise Corti, Deputy Director and Manager, Qualidata, Department of Sociology, University of Essex, Colchester CO4 3SQ, UK. E-mail: cortl@essex.ac.uk Tel: +44 1206 873058 Url: www/essex.ac.uk/qualidata/ 